\title{
Curating the Canon: Editorial Decision-Making, Bias and Privilege in Publishing
}

\author{
David Barker ${ }^{1 *}$
}

\section{${ }^{1}$ University of Derby, UNITED KINGDOM}

\section{*Corresponding Author: d.barker@derby.ac.uk}

Citation: Barker, D. (2021). Curating the Canon: Editorial Decision-Making, Bias and Privilege in Publishing, Journal of Cultural Analysis and Social Change, 6(1), 01. https://doi.org/10.20897/jcasc/11118

Published: July 31, 2021

\begin{abstract}
In September 2003, the independent publishing house Continuum launched a book series under the banner of "33 1/3". These were, in the publisher's own promotional literature, "short books about classic albums". But who decides what constitutes a classic album, and who decides which authors should write such books? Using an autoethnographic approach to analyse the curatorial thinking and strategy behind this book series, and through close analysis of the online discourse around it, the article innovates by exploring the commercial and curatorial practice of one publishing imprint in the first decade of the 2000s. By focusing closely on the work of one editor and drawing on primary data concerning book proposals that were accepted or rejected as well as reader reactions to those decisions, I illustrate how decisions are made and how editorial bias might impact the authorial voices that publishers choose to amplify. Finally, the article examines curatorial practice in publishing in light of more recent discussions of inequalities and imbalances of power (along both gender and ethnic lines) in the industry.
\end{abstract}

Keywords: publishing, evaluative judgements, ethics, taste, bias

\section{INTRODUCTION}

This article aims to bring into the open a set of publishing decisions that were made between 2002 and 2009 . The article will use as its case study a book series called " $331 / 3$ " - a collection of short books published by the New York and London based Continuum International Publishing Group (hereafter "Continuum"), each one of which took as its subject an album of recorded music ranging from Dusty in Memphis (Dusty Springfield) and Exile on Main Street (The Rolling Stones) to Sign O' the Times (Prince) and Paul's Boutique (The Beastie Boys). The series name "33 1/3" stems from the speed at which long-playing vinyl records spin on a turntable.

(The $331 / 3$ series continues to this day under the umbrella of Bloomsbury Academic - Continuum having been acquired in 2011. Since 2016 I have had no connection with Bloomsbury or the series and nothing discussed in this article should be taken as a reflection on any previous or current employee of either Bloomsbury or Continuum, other than myself.)

The aim of this study is to examine the publishing choices made during the first years of the series. There is a small but growing field of study about the editorial / curatorial function of book publishers, attempting to demystify why some books get chosen for publication and others do not. By focusing on this book series and my role in its creation, I hope to provide insight into such publishing decisions, and to expose how the biases of an editor can impact the types of books that make it to market. I aim to examine whether the series established certain expectations for readers, authors and booksellers which excluded non-white and non-male voices. 
Much of the existing scholarship around editorial decision-making includes (usually anonymous) views from current publishing employees. It is difficult, however, for these research subjects to be entirely honest about their instincts and tastes as editors. Anonymity does allow some openness (as seen in Saha and van Lente's report of 2020) but in the form of short quotes rather than sustained reflection and analysis. With the benefit of hindsight and the privilege afforded to me by no longer working in the industry ${ }^{1}$, I have the opportunity to go further here.

\section{AUTOETHNOGRAPHY AS A TOOL}

As mentioned, the $331 / 3$ series has been picked as a case study because I was its originating publisher and worked as its sole commissioning editor for the first several years of its existence. As a researcher, if I were studying the series I would endeavour to interview the editor who created and built it. So, I will be interrogating myself at times during this article. As per Chang (2008), I do this not with the aim of 'focusing on self alone, but...searching for understanding of others (culture / society) through self.' (Chang, pp.48-49)

I have chosen to use an autoethnographic approach for this study, and will be making use of - and contextualising - a range of sources including my own memories of how those books were commissioned, documentation from the time, as well as archival posts written by myself (as well as reader comments on those posts) from the series blog which was active for much of the period covered by this study and is still available to view online.

There is a broad field of scholarship which examines and reflects upon autoethnography as a method of research and which serves as a theoretical underpinning to this article (Denzin, 2003; Ellis and Bochner, 2000; Vickers, 2002; Reed-Danahay, 2009; Barton, 2011; Chang, 2008). It is not my intention here to survey that field, but one researcher I have chosen to highlight is Campbell, who has explored the benefits of autoethnography in her own work around legal education, and whose writing resonates on a few levels.

Arguing for the value of the autoethnographic method, Campbell (2016) suggests that "We need stories of lived experience in order to amass multilayered knowledge of a phenomenon, understand its truths and meanings and its place in the culture. The thick description embodied in an autoethnographic approach can help make sense of our own experiences" (p.98). There's a dual approach here that feels authentic: using autoethnography as reflective attempt to make sense of one's own experiences, on the one hand; and working to understand a broader phenomenon (i.e. a series of books) and its place in (publishing) culture, on the other. As a former publisher tasked at the time with commissioning authors and building a list, there is an opportunity now afforded to me by temporal distance and my current role as an academic. By unpicking my own decisions and interrogating what lay behind them, it should be possible to offer insight into the broader cultural phenomena that surround parts of the publishing industry - particularly with regard to editorial bias.

This method of research is not without pitfalls. Campbell (2016) warns that one risk is that the researcher might change or reinterpret their experiences under the microscope, to better 'suit the purpose of the story'. (p.100) This could be deliberate or it could be a result of memories having faded or shifted, as noted by Marsden and Squires (2019). I will try in this article to rely on documented evidence - but memory will be a valuable part of the story, too.

Given that these events took place almost 20 years ago, how reliable is my memory? Is there a temptation to recall my decisions more positively, to make me seem more enlightened than perhaps I was? According to Chang (2008), '....autoethnographers are expected to treat their autobiographical data with critical, analytical and interpretive eyes to detect cultural undertones of what is recalled, observed, and told.' (Chang, p.49) We will be relying at times on my own recall, but I shall be as critical and analytical as it is possible to be.

I was not working alone on the $331 / 3$ series. I was the sole editor until 2010 but even during those years I was working with colleagues in other parts of the company - in particular, from Sales, Marketing and Production. The series could not have functioned without valuable input from those colleagues and I need to be careful about how I frame that input within the context of this research. Campbell (2016) questions the dangers of how other people's stories might intersect with one's own, in such work. "It is inevitable that other people will be (in)direct participants in autoethnographic research. Even if I went on a year-long retreat into a cave without human company, I would naturally reflect on the people whom I had encountered in my life, those who moulded me, those whose advice I did or did not heed" (p.102). Editors in publishing do not work in a vacuum and there were many discussions during those years - as a tight-knit group of colleagues and friends in a small office environment - which fed into the series and its direction. I am confident, though, in stating that to a very large extent the concept of the series and the authors and subjects selected for publication were my decisions. Any bias we may discover will rest with me.

\footnotetext{
${ }^{1}$ Since February 2017 I have been a lecturer in publishing at the University of Derby.
} 


\section{THEORIES OF CURATION AND COMMISSIONING}

The literature devoted to editorial decision-making and curatorial processes can be divided into three discrete but somewhat overlapping categories.

First, what might be classified as memoirs by eminent publishing figures (including Unwin, 1926; Harrap, 1935; Warburg, 1959; Blond, 1971; Doubleday, 1972; Cerf, 1977; Korda, 1999; Maschler, 2005; Goodings, 2020), typically written more as autobiography than as scholarship, and full of anecdotes (and wisdom) about famous authors and literary scenes. These books do contain reflections on publishing processes but often the focus is on the more commercial aspects of the business, around profits, bookselling, discounting, etc.

Second, there is insightful work by researchers including Bhaskar (2016, 2019), Davies (2004), Rodgers (2017), Squires (2017), Ginna (2017) and others - all of whom are, or have been at some point, editors within the industry, faced with making commissioning decisions about which book projects to acquire or reject. Bhaskar has pursued the editorial function with the greatest theoretical vigour so far. His thinking around how editors curate in order to build their lists is of direct relevance here, in particular the concept of a 'unique editorial signature' (2019, p.229) which is developed by individual editors. I hope to explore this, certainly taking into account 'factors like gender, race and class...educational levels, personal beliefs... and temperament' which Bhaskar (2019, p.231) suggests all contribute to how an editor goes about the act of commissioning books and building a list.

Thirdly, we have contributions to the field - often rooted in sociology - by scholars from both inside and outside the loose discipline of Publishing Studies, who have chosen to include publishing and its editorial functions in their broader investigations (Powell, 1985; Bourdieu, 2008; Thompson, 2010; Stewart, 2018; Ramdarshan Bold, 2015, 2019; Greenberg, 2015, 2018; O’Brien, 2016; Saha, 2017; Saha and van Lente, 2020). Much of this work focuses on disparities and inequalities in the industry, from Ramdarshan Bold's pioneering work on representation in children's and young adult books to O'Brien's wider focus on the Creative Industries as sites of inequality and classism. Interestingly, much of this work prioritises fiction over non-fiction. It is, of course, essential that the creative stories told to readers represent diverse voices, but I argue that equal attention needs to be paid to diversity in non-fiction books (where expertise is often more important than narrative skill).

This article will contain elements of each of these three strands. There will be career recollections and reflections, but only in order to inform my thinking around the editorial function - which in turn will prompt further thoughts on the issue of diversity and bias in the publishing industry.

\section{PERSONAL BACKGROUND AND SERIES ORIGIN}

Privately educated and having grown up in Berkshire, I was a typical publishing industry entrant in 1996: according to the most recent Publishers Association survey, 26.1\% of respondents grew up in the south-east of England and nearly $20 \%$ of respondents attended a fee-paying or independent school - considerably higher than the national average for the UK. (Publishers Association, 2020) Did this background have an impact on my work as a commissioning editor? It seems essential to ask this, as per O'Brien et al: ' $\ldots$ given the dominance of the children of professionals and managers in publishing, what are the implications for English literary culture?' (2016, p.128).

Having moved from London to New York City in the spring of 2001 - five years after starting as an Editorial Assistant - with the remit of increasing the publishing output of Continuum's small US office, I was lucky to have the time to think creatively about what types of books I wanted to publish, under the broad umbrella of nonfiction about popular culture. Aside from increasing title count, what was also at the front of my mind was trying to make my job as fun as it could possibly be. (The concept of publishing as "fun" is one that I aim to explore in future research.) I spotted the chance to create a book series that might allow me to indulge my two biggest passions: books and music.

My focus was on building a list of books that might appeal to committed music fans. To that end, I put together a list of 100 albums that I thought might work from three perspectives: that readers might want to buy the books, that authors might want to write them, and that book and record stores might want to support them. I no longer have the original list but I can recall that it contained albums by (among others) David Bowie, Radiohead, Bob Dylan, The Beach Boys, Patti Smith, Bruce Springsteen, Joy Division, The Smiths, Joni Mitchell, and The Rolling Stones. It did not contain much, if anything, in the genres of hip-hop, R\&B, soul, disco, blues, metal, folk or pop.

The first six books, published in September 2003, were about albums by Pink Floyd, Dusty Springfield, Love, Neil Young, The Smiths and The Kinks. The authors were John Cavanagh, Warren Zanes, Andrew Hultkrans, Sam Inglis, Joe Pernice and Andy Miller. It was not a conscious decision to launch the series with six books written by six white men of about the same age as myself. I do not remember it even occurring to me that the author mix might be an issue. 
It is worth interrogating the extent to which my own tastes influenced the series at the outset. There is a considerable body of research around taste in the field of cultural sociology and while there is not the space to discuss it fully here, it is still useful to touch upon.

Pierre Bourdieu, in his analysis of the work of editors in one type of publishing (literary fiction, in France) discusses taste in the context of a curatorial strategy.

"A book's dual nature - as both a signifier and a commodity, a symbolic and an economic entity requires an editor to have a dual character, one that can reconcile art and money, love of literature and the pursuit of profit, by devising strategies situated somewhere between the two extremes of cynical subservience and heroic indifference to the house's economic needs." (Bourdieu, 2008, p.138)

Bourdieu's model of 'art and money' does not fit so neatly for editors working with non-fiction texts, or with more blatantly commercial books where the concept of 'art' might not apply so readily. In all sectors, though, one of the ways in which an editor is most likely to express their "love of literature" is to commission books that align closely with their own interests, as far as that is allowed within the publishing house's (or imprint's) remit. And when editors are, as the data tells us, overwhelmingly white and middle-class then we have one reason why so much publishing output might be targeted at those interests, those tastes. It is not the case that all editors are limited to their own experience of the world - there are examples of editors who work hard to publish different stories by different voices - but it is a default setting that can be easy to fall back on.

Another way of framing Bourdieu's 'dual character' is presented by Stewart (2018), in his analysis of taste and curatorial practice of editors at larger independent publishers. Stewart suggests that a 'portfolio approach' is used in list-building: a deliberate policy of commissioning a mix of books, some that are very close to that editor's personal tastes and some that are not - but which make commercial sense for that publisher to take on. (This has echoes of Childress' description [2012] of editors acquiring a blend of books that either capture economic or cultural capital.) I certainly recognise this approach in my own commissioning past but again, as with Bourdieu's framework, it feels more applicable to fiction. As with broader cultural discussions of publishing, fiction tends to dominate attention around curation and commissioning: we need to ensure that processes and patterns in the publishing of non-fiction are interrogated, too.

Childress (2012) in his study of how editorial taste intersects with use of BookScan sales data in US trade publishing, highlights how the "aesthetic sensibilities" (p.607) of editors play a key role in how books are acquired. He also argues that editors build up social capital within a publishing house by attempting to acquire books which they know most of their colleagues (other editors, staff in sales and marketing teams) will also support - thus creating an echo chamber of sorts in which the tastes of whole publishing imprints or divisions can settle into a groove with little risk of disruption. In her study of changing methods of commissioning in UK publishing in the digital age, Squires (2017) finds that editors learn to combine their personal taste with the corporate environment: what might feel like a gut reaction may well be an equally instant awareness of whether a manuscript one likes might fit the company's list.

Although I recognise that personal/corporate hybrid from other commissioning in my career, at the outset of the $331 / 3$ series it did not apply for the simple reason that the series bore little relation to the rest of Continuum's output. The series, at the very start, was shaped by my own personal taste (the first six titles featured three of my favourite artists in The Smiths, The Kinks, and Love - and another of my favourite singer songwriters, Joe Pernice, as an author) and by a set of rudimentary assumptions about the possible readership for a series of obsessive books about music. I do not remember being challenged by any colleagues at the time about the white, male nature of the initial list of books - although it is possible that this occurred and I have forgotten it. My excitement about the project and its commercial potential was probably enough to encourage others to support it. We were also a small, tight-knit group of colleagues at that point which might have made it more difficult for anyone to raise the issue of bias with me.

It is also worth mentioning here - not as an excuse for any possible bias in the series but as further context for the cultural field with which the books were overlapping - the lack of gender and ethnic diversity in classic and indie rock. Sahim (2015) in her discussion of the whiteness of indie music (and "indie culture" more broadly) demonstrates that a network of artists, labels, producers is backed up by written coverage of the scene to reinforce a monoculture that seems designed to make outsiders (in her case, as a woman of colour) unwelcome. Schaap and Berkers (2020) explore the attitudes of American and Dutch rock music fans from a range of ethnic backgrounds towards their participation in that scene, finding that non-white rock fans report reactions of surprise, suspicion and scrutiny - again, not the unquestioning welcome that white participants typically feel. The music industry itself, like publishing, has often been accused of a lack of diversity. Smith et al (2021) report that in the U.S. music business, women of colour account for only $3.2 \%$ of senior executive roles despite the fact that the artists represented by those businesses are considerably more diverse in terms of both gender and ethnicity. And Wilson (2007) observes that for indie rock in particular, beyond issues of diversity mentioned above, social class can 
exclude broader participation, too - arguing that this genre of music tends to be "bookish and nerdy" and packed with allusions and concepts that assume a certain level of cultural capital. This offers some further background to the attitudes and assumptions that $\mathrm{I}$, as a white, male, middle-class and highly educated editor, was bringing to my curation of the $331 / 3$ series from the outset.

\section{COMMISSIONING PROCESSES AND EARLY SERIES PROMOTION}

A year and a half into the series' life, 33 1/3 books were being published in batches at a quick pace. By this point, artists covered in the series included Jimi Hendrix, Abba, Prince, Joy Division, The Velvet Underground, The Beatles, James Brown, Jethro Tull, Radiohead, The Replacements, The Rolling Stones, The Beach Boys, Led Zeppelin and The Ramones. Further titles were about to publish on albums by Jeff Buckley, R.E.M. and Elvis Costello. In terms of the authors involved, all but two were male (writing about Abba and Jeff Buckley) and all were white except one (again, writing about Jeff Buckley).

I had moved from the original proactive commissioning model (initiating contact with potential authors) to a more reactive one. The series gained a lot of coverage during its launch period, so by the summer of 2004 I was receiving 5-10 emails per week from interested writers. How was I sifting through these queries? Often I was swayed by a writer's existing profile: did they have a track record of writing articles for national or regional newspapers? Had they written for the music press? Did they have an online platform with a following? There were commercial considerations involved in those lines of thinking and there was also the suggested artist/album to consider, each time. I was not consciously choosing books about albums I liked but it certainly helped to sway some $50 / 50$ decisions at times.

Was it inevitable that this initial process of curation would lead to a roster of white, male authors? I do not recall any thoughts of pushing back against that inevitability. It was easier not to think creatively about the voices I was offering a platform for.

The commissioning process flows in more than one direction. I, as the series editor, was selecting authors and proposals for publication. Equally, writers were proactively pitching their ideas to me: there was a selection process in play before the emails and phone calls reached me. Bourdieu (1985) writes about this 'preselection' process, arguing that authors develop specific perceptions of publishers during their own process of deciding where to submit or who to contact.

What was the image that potential authors received from the start of the series? Looking at the books published in 2003 and 2004, most authors might have concluded that we were looking for a combination of classic rock and pop with a sprinkling of mildly alternative artists added to the mix. The series had included Prince and James Brown by that point, but the output (in terms of subjects and authors) was still overwhelmingly white and male in its focus. Powell (1985) sees the author selection process as a kind of mating ritual, with editors and authors hoping to find overlapping aims - although to me that suggests more authorial power than many writers feel they have in the publishing relationship. Powell also writes about authors seeing publication as a way of enhancing their careers; but this too can flow in both directions. Often editors are looking to enhance their career prospects by seeking out content which might boost their reputation within the company or the wider industry. And under pressure to hit targets (as described by Thompson, 2010), it is tempting for editors to take the occasional shortcut by gravitating towards the types of content with which they are already familiar.

Such cultural familiarity can also be seen in promotional methods. With $331 / 3$, any mainstream advertising was beyond our budget. Instead, we printed up a couple of thousand postcards to introduce the brand and the first six books and decided to hand those out to concertgoers in New York City in the summer of 2003.

Most of us who worked on the series lived in Brooklyn, where one of the major summer events was the "Celebrate Brooklyn" programme of shows in Prospect Park. I decided that this would be an ideal place to let music fans know about the series for the first time. Of the 26 events on the programme that summer, I chose to hand out the postcards at a concert by Belle \& Sebastian, at that time my favourite band, so a show I would have attended anyway.

It is possible to argue that this decision made commercial sense: two of the launch titles in the series were on albums by Love and The Smiths, both bands beloved by Belle \& Sebastian and hence by many of their fans, too. (Neither would it be a stretch to imagine their fans also being into The Kinks, Pink Floyd, Dusty Springfield, perhaps even Neil Young.)

By focusing on this audience for the series' first promotional push, we were reinforcing the lack of diversity already apparent in the artists and authors selected. Other events that summer at which promotion could have happened included shows by Joan Armatrading, Blackalicious, Erykah Badu and Café Tacuba. Already at that point (before the series had even launched) I had decided that those audiences might not be the "best fit" for the books we were going to publish. It was far easier for me to stay within my comfort zone of broadly white, bookish readers who were just like me. 
In their report (2020) about diversity in UK publishing, Saha and van Lente suggest that those involved in commissioning content 'need to reflect more critically on the assumptions that frame their approach and challenge them where necessary.' (p.15) I was not doing this, at the time I was launching the $331 / 3$ series. There was no element of critical reflection in my job. It was simply a matter of commissioning and acquiring book projects, getting them approved in meetings, and hitting my targets each year. (For the books in the series, the decision was taken to avoid second-guessing which titles might outperform others and instead we projected an average global first-year sale of 5,000 copies each. Although some sold better and others sold worse, as an average that turned out to be fairly accurate. Our publishing meetings largely operated as rubber-stamping individual books in the series.) It would be easy to say that in the busy cut and thrust of publishing, there was no time for reflection; but the reality is that - at that point in the early 2000 s - there was no impulse that I can remember to challenge my own assumptions.

The dynamic around the series and the method of commissioning started to shift in 2005 with the start of the series blog - the point of which was not only to promote the series but also to demystify and democratize (in my eyes) the publishing process, to open it up as much as possible. The blog launched by listing the books and authors published and due to publish in the coming months. It soon developed into a medium for informing readers about new titles, updates as to which book and record stores were stocking the series - and an increasing amount of more personal content. There were posts about what songs my father wanted to have played at his funeral; about short stories I'd enjoyed reading; about new bands I was enjoying; about my music teacher at school; about my dislike of vegetables, and about the death of the footballer George Best.

Scrolling again through these hundreds of blog posts between 2005 and 2009, I am struck by how consistent they are in their tone and their likely appeal to a narrow cross-section of readers. It would be possible to argue that this was smart publishing. The blog was an integral part of the series' identity during those years, seeing a considerable amount of online traffic and even being covered as "Blog of the Week" in the UK's Sunday Times. As smart as it may have been as a way of promoting the series, the blog served to amplify my own (white, male, middle-class) voice at the expense of others. From a potential author's perspective, the content of the blog might have felt familiar, comfortable and inviting - or it could have looked exclusive and closed. One editor interviewed in Stewart's 2018 study of independent publishers puts it bluntly: ' ...people will come to your website, and look around, and then they'll see nothing but white, and they'll be like, well this isn't for me' (Stewart, 2018, p.10). It isn't simply in the books they choose to publish that publishers need to be inclusive. The paratexts around that publishing need to be inclusive, too - including the language and cultural references used on websites, in back cover copy and on social media.

The blog became more than a way of engaging readers and promoting the series when I started using it as a way of commissioning content. In the next section, I will analyse how that process worked as a method of curation, examining the range of authors and subject matter that resulted from the open calls and determining to what extent - if any - the series shifted its identity as a result.

\section{PROPOSALS SUBMITTED: DATA ANALYSIS FROM 2005 TO 2009}

The following sections of this article will break down the submitted proposals received via the three open calls in the years 2005 (Round 1 below), 2007 (Round 2) and 2008/9 (Round 3), with the aim of assessing how closely the books which were commissioned mirrored the mix of the proposals received, in terms of author profiles and subject matter. In other words, was I using the privilege of my editorial role to make my publishing representative of the proposals I received? Or was I still subconsciously pursuing my own agenda for the series, under the guise of being open and democratic?

The graphic in Figure 1 shows the number of proposals received across the three open call windows, by musical genre. It shows clearly how the overall numbers increased after the first window in 2005 and also how proposals for books about classic/indie rock acts dwarfed those for books about other types of music. These numbers are not rigidly scientific as not all of the albums suggested fall precisely into one musical genre but I have tried to be as consistent as possible in classifying them and I am confident that these ratios are representative.

The first call for proposals on the blog was on 21 September 2005. My aim was to be as open as possible, as well as to funnel potential authors into a window of time - in order to slow the stream of emails from people asking to write for the series. In terms of openness, I do not recall framing this in terms of a deliberate, proactive drive for diversity. It was more in the sense of 'anybody should feel welcome to have a go at writing for the series'. I remember feeling excited by this change of commissioning strategy and hoping that it would make readers feel more connected to the series.

This initial post was followed on 1 December 2005 by a list of proposals which had been received: the first fruits of a commissioning method which would become one of the series' hallmarks in the following years. 


\section{Proposals received by musical genre}

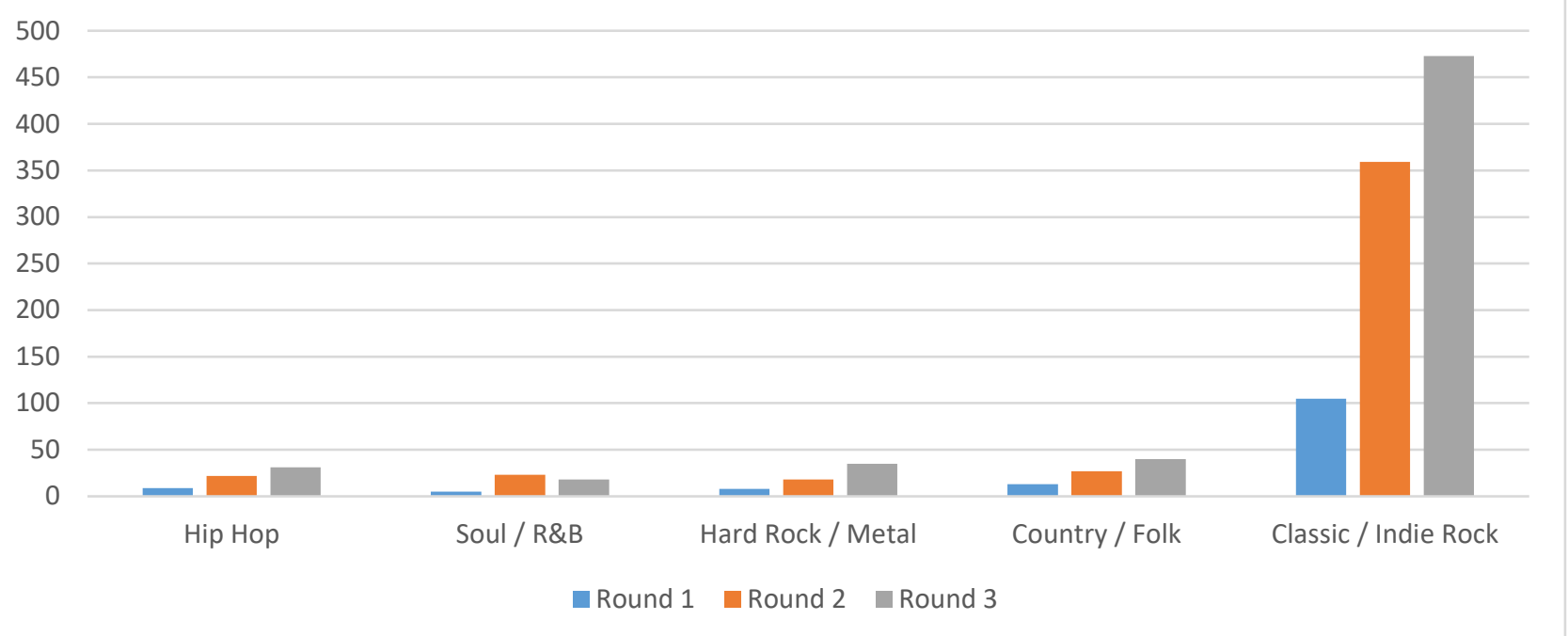

Figure 1. Proposals received by musical genre.

\section{Late 2005 call for proposals}

During that first call for proposals in late 2005, 140 were received. In terms of the artists covered, $6 \%$ fell under the genre of hip-hop, 3\% were soul / R\&B / reggae / funk, $6 \%$ were hard rock / metal, $9 \%$ were country / roots / folk music, and the remaining $76 \%$ fit the broad classic / indie rock / pop category as described earlier. Considering that some artists received more than one proposal (The Flaming Lips received four, for example), we can break down the gender of the artists as follows: 9\% of proposals were for books about solo female artists, allfemale bands, or clearly female-fronted bands. The remaining $91 \%$ of proposals were for books about male solo artists or all/mostly male bands.

In the comments from readers below the blog post announcing the list of artists for whom proposals had been received, there was one mention of the lack of metal artists on the list - quickly followed by: "Still very few women...very interesting." (Anon, 2005) The remaining comments covered the publishing decision-making processes involved, for example:

"I'm amazed that bands like Arcade Fire and Libertines are being pitched. Not that I don't like them, but classic albums need time and historical perspective to be considered classic."

and

"I would love to be a fly on the wall for the selection process. You must have some serious aesthetics/audience/series cohesion mathematics to perform to get the answers here."

A few weeks later, I announced on the blog that we would be offering contracts to 21 of the proposals received. Of those 21 books, $24 \%$ would be written by women and $76 \%$ by men - a more balanced ratio than in the submissions received. $10 \%$ of the authors selected for publication were non-white. In terms of the music being written about, all the artists were white except for two: Stevie Wonder and A Tribe Called Quest. And five of the artists were female (or female-led) with the others being male bands or solo artists.

It would be possible to argue that the 21 books commissioned during this open call represented a more diverse range of authors and subject matter than the pool of 140 proposals originally received. By this stage, if the series was shifting in its focus it was towards a few more left-field choices (Celine Dion, The Minutemen, Throbbing Gristle, Lucinda Williams) - but in terms of diversity it still remained closely aligned to my own experience and tastes instead of taking the opportunity to publish more writers of colour and to tell more stories about artists from diverse backgrounds.

\section{Early 2007 call for proposals}

The next open call for proposals took place a year later, in January 2007. Prospective authors were no longer able to submit a proposal for a book about an artist that had already been covered by the series. (Was this an attempt to encourage more diverse submissions, or simply a commercial decision to prevent cannibalisation of our 
own sales? I cannot remember.) In mid-February the blog announced the list of proposals received under the heading "Maybe we'll do both of the Osmonds albums".

The total list included 449 separate proposals. In terms of artist gender, 9\% were solo female artists, all-female bands, or female-fronted bands. The remaining $91 \%$ were solo male artists, all-male bands, or mostly male bands. In terms of musical genres, $5 \%$ fell under the genre of hip-hop, $5 \%$ were soul / R\&B / reggae / funk, 4\% were hard rock / metal, $6 \%$ were country / roots / folk music, and the remaining $80 \%$ fit into the broad classic / indie rock / pop category.

There were over 150 comments left below the blog post which listed the proposals, showing a large amount of reader participation with the series at this point. Most of the comments were from people listing what their own book choices would be, from the list. There were no mentions of the list's overwhelming focus on white rock and pop music - one interpretation of which might be that these engaged followers of the series were being offered what they had come to expect.

In March 2007, I announced on the blog that we would be offering contracts to 21 of the proposals received. Of those, $9 \%$ would be written by women and $91 \%$ written by men. $9 \%$ of the authors were non-white. There was a notably higher proportion of non-white artists than the series had previously engaged with $(29 \%$ of the books signed up), with albums chosen by Funkadelic, Nas, Israel Kamakawiwo'ole, Public Enemy, Wu-Tang Clan and Outkast. In stark contrast, only one of the artists (Tori Amos) was female.

The books commissioned in this 2007 open call certainly showed a more diverse range of subjects and was moving away from my personal tastes, to an extent. It seems like there was an effort to include more hip-hop in particular - although some of those books never made it to fruition due to authors later dropping out.

In terms of comments left by readers below the announcement of the 21 titles signed up, there was an even (and at times acrimonious) split between those who thought the list looked great, and those who didn't like it, mainly because too many of the artists were "obscure". One anonymous commenter noted the near total lack of female authors as problematic:

"David, very disappointing that there aren't more women authors, it doesn't seem right. From the number of proposals you received I'm sure there were more women, and more music by women for that matter." (Anon, 2007)

Although I did respond to quite a few of the comments below the announcement of the 21 books chosen, I chose not to respond to that one. At a distance of fourteen years I cannot remember precisely why, but I would assume that it was a combination of feeling "guilty as charged" and a reluctance to get into an online debate that would have reflected badly on me.

\section{Late 2008 call for proposals}

The next open call for proposals took place at the end of 2008, shortly after the economic crash. This time, authors were able to submit proposals for albums by artists who had already been covered in the series. By midJanuary 2009 the deadline had passed and I announced on the blog a list of proposals received under the heading "The Longlist".

There were 597 separate proposals. In terms of artist gender, $8 \%$ were solo female artists, all-female bands, or female-fronted bands. The remaining $92 \%$ were solo male artists, all-male bands, or mostly male bands. In terms of musical genres, $5 \%$ fell under hip-hop, $3 \%$ were soul / R\&B / reggae / funk, $6 \%$ were hard rock / metal, $7 \%$ were country / roots / folk music, and the remaining $79 \%$ fit into the classic / indie rock / pop category.

There were over 250 comments left below the blog post which listed the proposals, showing an even higher amount of reader engagement than previously. Again, many of the comments were from people listing what their own book choices would be - but there were also flashes of debate around what readers thought the series should be doing. Two anonymous commenters pointed out the series' lack of books by women and about women, for example: "There needs to be more female artists / more female writers represented in this series...the proposals have to be chosen on merit, what will sell, how good the angle is...but come on $331 / 3$, there MUST be some female authors from this list that fit those criteria?" (Anon, 2009)

Others argued that more recent albums shouldn't be considered for the series, because "classic albums" need time to achieve that status. One person commented that the series needed more books about soul music. Another commenter noted the narrowness of the hip hop proposals on the list, comparing that to the breadth of the list's music by white people. Interestingly it was the writers who were criticised for being boring, instead of the series itself (or myself, as editor). Several commenters suggested that the series was in danger of catering exclusively to rock snobs or indie hipsters.

In May 2009, I announced on the blog that we would be offering contracts to 11 of the proposals received. This was a considerably lower number than in previous open call processes: the economic crash of September 2008 had a negative impact on Continuum as well as the rest of the publishing industry. Still, my reaction now on 
revisiting this announcement is that choosing only 11 proposals from nearly 600 submitted feels like a poor return on time for those writers.

Should I have been clearer about this at the outset of the open call window, about how few authors would end up receiving contracts? And is this perhaps part of the gatekeeping role that publishers could demystify for authors? Data about the numbers of proposals accepted and rejected each year by publishers and agents could be made public. Academic publishers often do this, making public their "rejection rates" as a way of trying to demonstrate the quality of their output, but I have seen few attempts from trade publishers to discuss this openly. Crisp (2017) wrote briefly about one imprint and showed that of 503 submissions to Tor UK over a period of five months, four books were signed up. Such transparency could feed into useful discussions around diversity and bias, as well as around the likelihood of earning a living as a (traditionally published) author. There will be sensitivities around this but that is part of the underlying problem: if publishers and agents have nothing to hide in terms of their commissioning practices then there should be no such concerns around making the data available.

Of the 11 books I signed up in May 2009, ten would be written by men and only one by a woman. Two of the 11 authors were non-white. In terms of the music being written about, only one of the artists was non-white (Aretha Franklin) and only two of the artists (Aretha and Liz Phair) were female.

In contrast to the previous open call, the 11 books commissioned here showed a retreat from opening the series up to a broader range of content. My reaction, undertaking this research now, is one of embarrassment. Six years after the series started, I was still mostly signing up books about white men, written by white men. I have zero recollection of this being a deliberate strategy but neither do I recall thinking that I should be doing something about it. A charitable interpretation might be that the economic crash prompted a safety-first approach to commissioning new books in the spring of 2009. Some of the artists chosen do back that up (The Rolling Stones, Johnny Cash, Radiohead, AC/DC, Aretha Franklin) while others don't (Dinosaur Jr., Slint, Ween, Portishead). There were perhaps, echoes of this conservative approach in 2020 when the Bookseller reported publishers as looking for guaranteed hits on the back of the disruption caused by COVID-19. (Chandler, 2020)

In terms of comments left by readers below the announcement of the 11 titles signed up, there was some vigorous debate between those who found the list disappointing and those who were still supportive of the series. One comment in particular stands out, arguing at some length that the demographic of people who might want to write an obsessive book about one album is likely to be white, male and college educated - and that the books being signed up might therefore reflect the ratio of submissions received. But this is surely reflective of the $331 / 3$ series and its identity over its first six years. Why would (for example) a young, black, female music writer even have considered the series a welcoming space back in 2008, given its near relentless focus on books about college rock and classic rock written by white men?

After this open call in late 2008 / early 2009, there was a long gap. Continuum at that point was transforming itself into a purely academic publishing company and the $331 / 3$ series didn't fit that identity neatly. Continuum was acquired by Bloomsbury in the summer of 2011, to bolster the latter's academic publishing depth and capability. In late 2012 another open call took place but by that point I was handing over editorship of the series to a colleague and my role at Bloomsbury was changing.

I won't, therefore, analyse that submission window in any detail here but we will see its impact (and the impact of subsequent open calls, post-2013) during the next section of this article. I don't intend to discuss the work of my successors on the series but it can be instructive to compare output during the early years when I edited the series and the later years when it was edited by others.

\section{VARIANCES IN SERIES DIVERSITY DURING MY EDITORSHIP COMPARED TO LATER YEARS}

The graph in Figure 2 shows the number of female authors published by the series annually, from 2003 through to 2019. The point at which I stopped having a direct influence on what was being signed up was 2012. It's clear from this graph that the subsequent series editors (both of whom were women) took a more proactive approach to signing up female authors.

The graph in Figure 3 shows the number of female artists covered by the series annually from 2003 through to 2019. Again, there is a clear trend here that the years after 2012 saw a more proactive approach to signing up books about female artists. 


\section{Number of female authors as a \%}

60

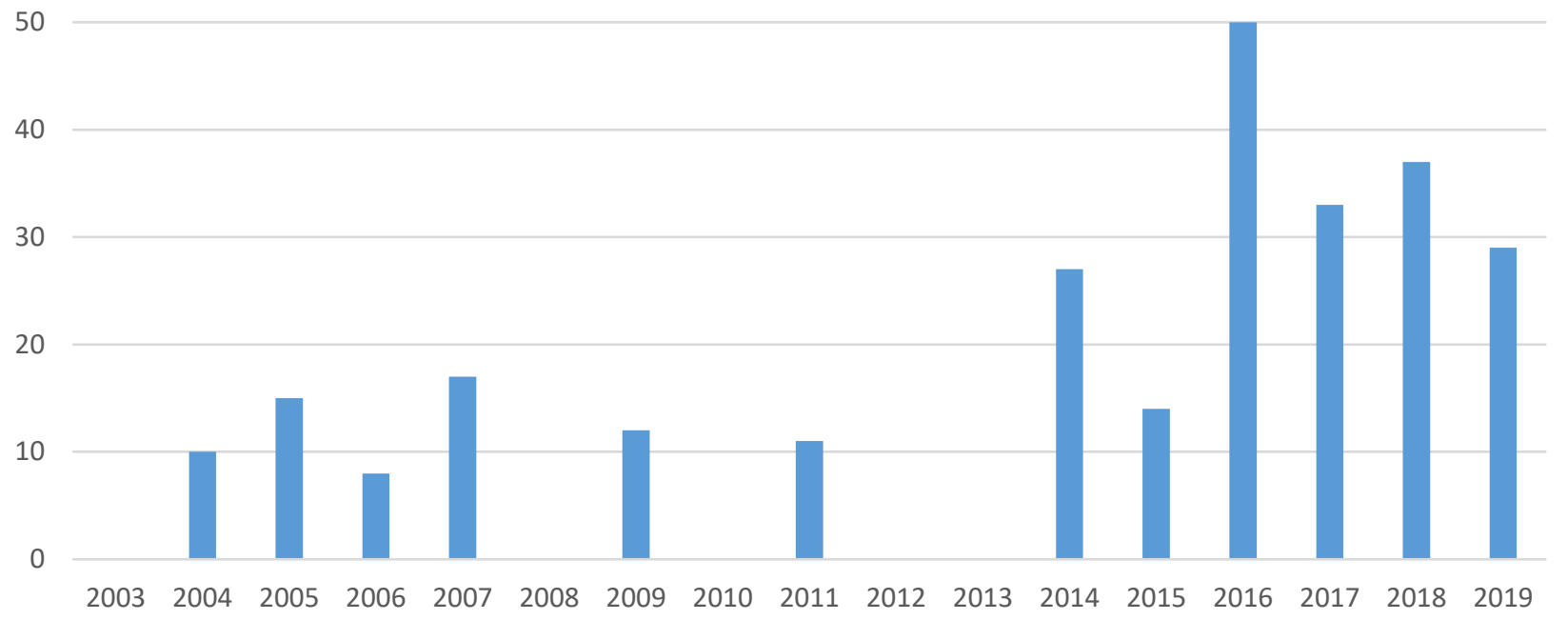

Figure 2. Number of female authors published by the series annually, from 2003 through to 2019.

\section{Number of female artists as a \%}

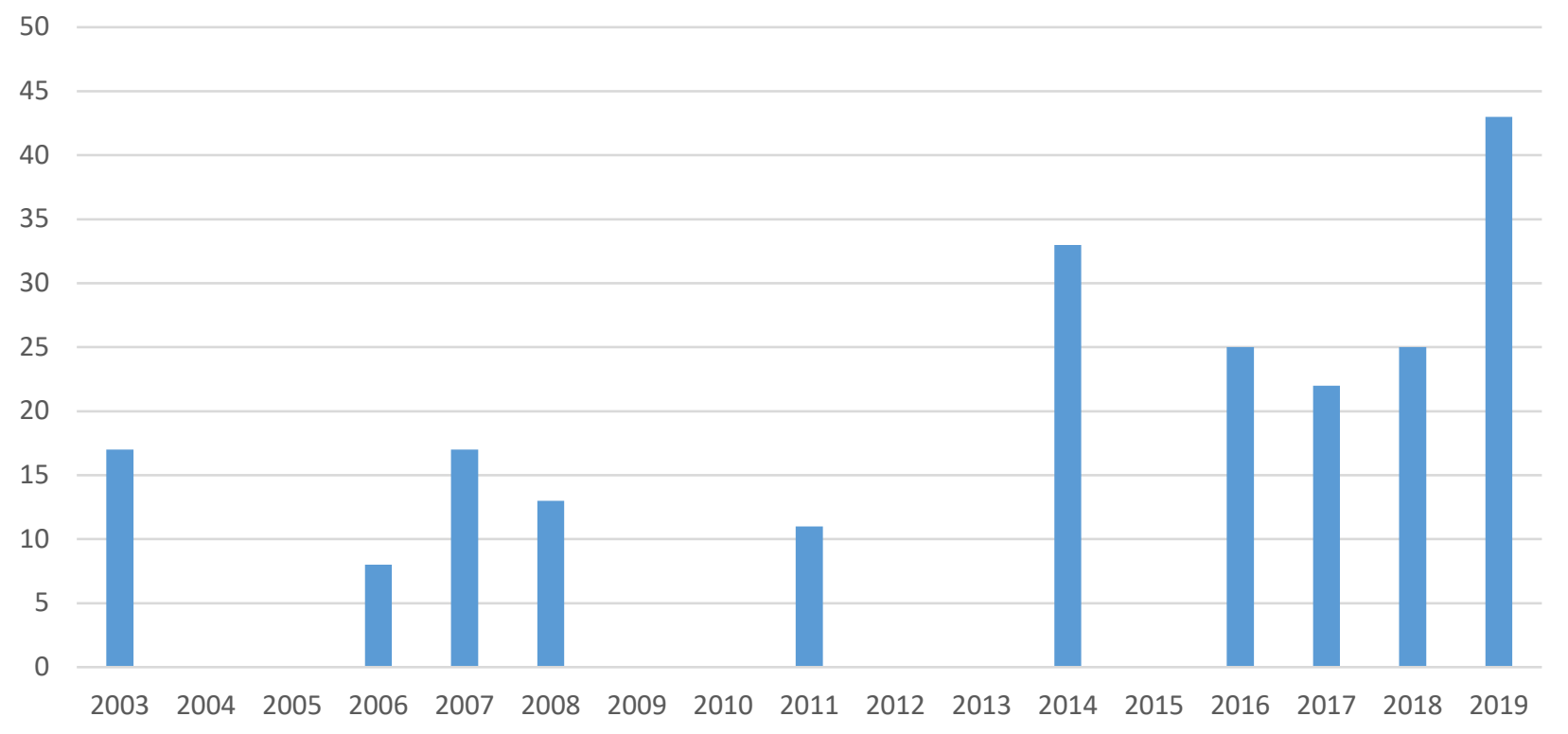

Figure 3. Number of female artists covered by the series annually from 2003 through to 2019.

The graph in Figure 4 shows the number of non-white authors published by the series from 2003 through to year 2019. There is less of a divide here between the results of my editorship and the years that followed, although a strong hint in 2017 that the series was working to be more inclusive.

The final graph in Figure 5 shows the number of non-white artists covered by the series from 2003 through to 2019. Again, there are indications here that the years after my editorship saw a more consistently proactive approach to signing up books about non-white artists. 
Number of non white authors as a \%

35

25

20

15

10

5

0

$200320042005 \quad 2006200720082009201020112012 \quad 2013 \quad 2014 \quad 20152016201720182019$

Figure 4. Number of non-white authors published by the series from 2003 through to year 2019.

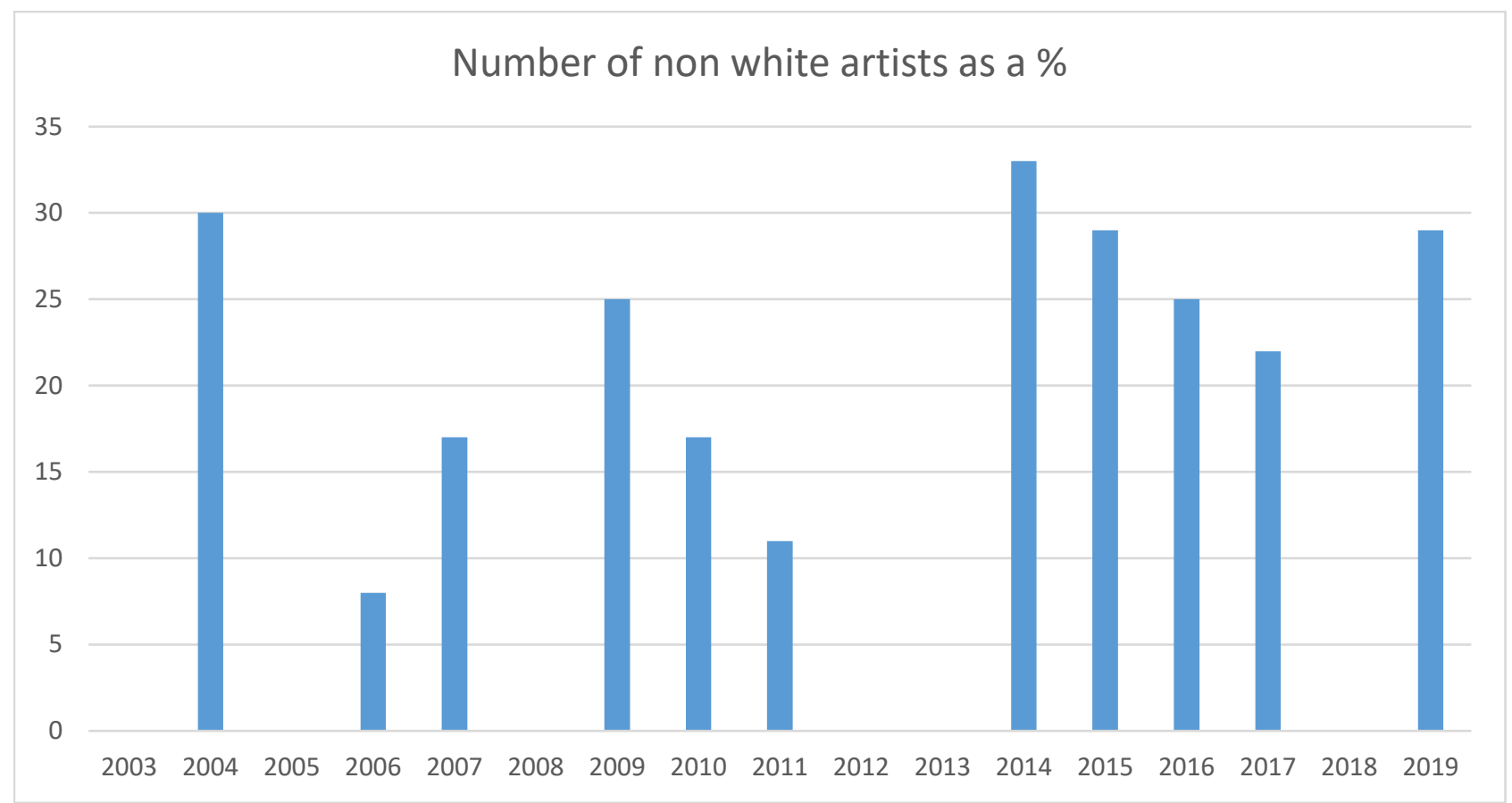

Figure 5. Number of non-white artists covered by the series from 2003 through to 2019.

These graphics demonstrate, to varying degrees, that the series became more diverse along gender and ethnicity lines after my editorship ended. This is difficult for me to write about, as the narrative I had constructed for myself was that although the series did start out being very monocultural, by the later stages of my direct involvement in commissioning it had become much more welcoming and inclusive. The data doesn't support that, and this failure was my responsibility. In order to explore a little more of the possible publishing psychology behind it, in the next section we will interrogate my thinking around sales figures and projections in the series. 


\section{SERIES SALES EXPECTATIONS AND BIAS}

The resurgence of the Black Lives Matter movement in 2020 gave rise to several articles and reports which were sharply critical of the publishing industry. Much of this was focused on employee diversity as well as gatekeeping by agents and editors. There were also insightful discussions around how the industry uses "comparable books" to predict sales of new titles.

Mahey-Morgan (2020) argues that assumptions about sales forecasts for books by non-white authors are often misleading, as previous publications by writers of colour may well have been inadequately promoted - or promoted to the wrong audience. Saha and van Lente (2020) in their report find similar practices. In one particularly illuminating section they describe how it's possible to use 'comparable' sales data on previous books in order to reinforce an editor's bias about certain types of books or authors.

This fits with my own interior monologue about the $331 / 3$ series, every time I studied the sales data. (The blog had a regular 'league table' feature, in which I ranked all titles in order of sales units, so I was constantly aware of which books were selling well and which weren't.) The league table I posted on 7 November 2007, for example, lists 49 books published in the series to that point, in descending order. The top-selling books are on albums by Neutral Milk Hotel, The Beatles, The Kinks, The Smiths, The Rolling Stones and Led Zeppelin - three of which can be partially explained by being among the first batch of books published in the series. These squarely fit the classic / indie rock template for which the series had become known. At the bottom end of the table, there are books about James Brown, Abba, Sly and the Family Stone, The MC5, Stevie Wonder, Joni Mitchell, Guns N Roses and A Tribe Called Quest.

I remember trying to figure out why these books hadn't worked as well as others. To take one example: when analysing disappointing sales of the books about Joni Mitchell and James Brown, my thought process was roughly: People who listen to James Brown probably don't buy books about him, and I must have chosen the wrong Joni Mitchell album to publish a book about.

My self-questioning at the time didn't go any deeper than that: a problematic assumption that fans of James Brown's music were less likely to buy books about it, while fans of Joni Mitchell must surely live in houses festooned with books. I remember framing it in my mind at the time as a "rhythmic / dancing music" vs "literate / bookish music" dichotomy but there was racial bias in play here. As Saha and van Lente (2020) observe of beliefs held within the UK publishing industry: "There also remain suspicions over whether racial and ethnic minorities read, or at least to the same extent." (p.10)

Part of my bias stemmed from cultural ignorance. I was aware that there were more famous Joni Mitchell albums we could have chosen, because I knew a fair amount about her music; while about James Brown's body of work, I knew very little. As Mahey-Morgan (2020) argues, 'the industry has a history of letting down Black and brown writers through monochrome work forces who don't know how to speak to different audiences.' I had not even gone that far, however: instead of finding a Black writer to tackle the work of James Brown, I had signed up a middle-class, Harvard educated, white male author.

Did the relatively poor performances of the James Brown, Sly Stone and Stevie Wonder books make me reluctant to sign up more books about other non-white artists? It certainly contributed to my lack of confidence around being able to predict strong sales for such books. I knew enough about indie rock to be certain that a book about Neutral Milk Hotel would sell well but my knowledge of similarly cultish soul, R \& B and hip hop acts was minimal. In a way it became a self-fulfilling prophecy: books I signed up about non-white artists weren't published with any confidence - and if you don't publish a book with confidence, to the right readership, then its chances of succeeding in a crowded marketplace are vanishingly small.

There are other factors in play in the publishing ecosystem. The series was primarily supported by independent record stores in the United States. These connections did not overtly shape my editorial choices but did perhaps add to the loop of feedback when re-orders kept coming in for books about certain artists which were popular with those stores' clientele (examples being Neutral Milk Hotel, Joy Division, The Velvet Underground, Guided By Voices, and The Ramones). The same blog post referred to above also mentioned a promotion that Barnes \& Noble were running with the series in late 2007, bundling together a book from the series with a CD of the relevant album. The books selected by B\&N were those about The Beatles, Led Zeppelin, Neil Young, Bruce Springsteen and Jeff Buckley: evidence, I would suggest, that the biggest bookstore chain in the US at that time was as focused on the monocultural aspects of the series as I was. The music books buyer at Barnes \& Noble was interested in the series, but would look up their sales history of other books about musicians or bands to help with her decisionmaking - so if their internal systems showed poor sales for books about an artist, our book would not be ordered. This is one small example of the centralised book buying power which all bookstore chains use to some extent and which is flagged up by Saha and van Lente (2020) as another area in which the publishing ecosystem favours well established norms. (Their report focuses on non-white authors of fiction but the same issues apply to non- 
white authors of non-fiction and also to non-fiction about subjects which might lie outside of a buyer's comfort zone or cultural awareness.)

\section{CONCLUSION}

This has been a difficult article to research and write. My memories of the period covered are uniformly positive. As mentioned earlier, creating and curating the $331 / 3$ series was fun. I had the chance to work with brilliant authors and colleagues to build a series of books which I was proud of and which entertained and informed - and occasionally infuriated - its readers. Reflecting now, it is striking just how unaware I was of how my editorial decisions over a period of years combined to create a space that was so unwelcoming to writers and readers who were female or non-white.

There are limitations to this study. It would have been instructive to be able to compare the gender and ethnic backgrounds of all the writers who submitted proposals to the series with the projects I eventually signed up during each open call, in order to gain a deeper understanding of any particular bias I was showing towards authors. It would also have helped greatly to have the original list of albums I created at the start of the series' life. Neither of these gaps, in my view, detract too much from what the evidence here tells us.

Also, this is one specific case study, covering events which occurred several years ago. It is very possible that editors now are being more inclusive in their publishing decisions - the available data shows improvements in some areas but not in others. (Penguin Random House UK, for example, across both its staff and its authors / illustrators, comes in at least three times higher than the national average in terms of people having attended feepaying schools.) I would like to think that conversations within publishing companies have moved on since the early 2000s and there are encouraging signs that this may indeed be the case.

The key point here, though, is that at no point was I doing my non-inclusive commissioning work deliberately. There was no conscious plan to make the $331 / 3$ series a space dominated by white, male voices. And there were no checks and balances in place to prevent this from happening.

Undertaking this autoethnographic research has reinforced for me the position of privilege that commissioning editors have in the publishing industry and how easily that position can be abused. I should have figured it out myself, of course, but at no point did any senior figures tell me about the responsibility that needs to go along with the role of commissioning (and rejecting) books. There was no training and there were no audits in place beyond the simplest commercial ones - only an assumption that I would bring in books that would generate revenue for the company, within the confines of that list, that imprint, that division. Any words of advice from managers and senior colleagues that I had received since starting my entry-level role in 1996 had all focused on the more administrative side of working in publishing: how best to manage my time, what methods to use when chasing up a late manuscript, and - once I started commissioning - various tips around ways of finding and approaching potential new authors.

It never occurred to me when I became an editor that the role which would occupy the next 20 years of my life should revolve around amplifying the voices of authors. Neither did it occur to me that by choosing to amplify some, I was prioritising those voices over others. I never realised that even if you are dimly aware of the need to reflect society in your publishing decisions you can still demonstrate cultural incompetence in how you go about your commissioning. Whether an editor is working with non-fiction about music or travel, nature or politics, sport or history, religion or humour, or whether an editor is looking to publish poetry or crime fiction, Young Adult novels or picture books, literary fiction or romance, the privilege and the responsibility are still the same - and this needs to be drummed into editorial staff from the day they start as assistants.

Again, this is not to deflect from my own failings, but if publishing companies are serious about increasing the range of what they publish then this type of editorial training feels like an essential step. Early signs from discussions around the resurgence of the Black Lives Matter movement in 2020 were positive. Commitments from the heads of Penguin Random House UK and Usborne in particular seemed to acknowledge the need for much greater responsibility around which voices get published. To hear a children's publisher unequivocally state that 'we are in a position of privilege and influence and we must use that' (Usborne, 2020) does appear to demonstrate increased awareness of curatorial responsibility. Similar language is used throughout the statement put out by Penguin Random House UK. Describing a 'profound sense of responsibility' (Weldon, 2020), the document also includes a commitment to mandatory training around inclusivity and anti-racism. It also includes a commitment that PRH UK's acquisitions will closely reflect UK society by 2023 although there is no mention of how that goal might be audited or enforced at the level of each individual editor.

The "Rethinking 'Diversity" report (2020) offers ample evidence to suggest that publishers 'need to challenge their own assumptions about whether publishing truly is a meritocracy.' (Saha and van Lente, p.17) This is the trap I fell into with the $331 / 3$ series. The assumption I made was that the open call process created a level playing field for all interested authors. But by framing the series from the start as very much focused on white, male rock music, 
and by conceiving of the blog as a space to showcase aspects of my personal tastes, certain parameters had already been established - for readers, for bookstores, and for prospective authors. As a thought experiment, imagine if the first six books in September 2003 had been written by a mix of women and men from diverse backgrounds, and the subjects had been Prince, Aretha Franklin, Public Enemy, Bjork, The Beatles, and Blondie. As a set of six books, that would have been just as commercial and could have shaped the future direction of the series in very different ways.

\section{REFERENCES}

Bhaskar, M. (2016). Curation: The Power of Selection in a World of Excess. London: Piatkus.

Bhaskar, M. (2019). Curation in publishing, in A. Phillips and M. Bhaskar, M. (eds), Oxford Handbook of Publishing (pp.227-243). Oxford: Oxford University Press. https://doi.org/10.1093/oxfordhb/9780198794202.013.6

Blond, A. (1971). The Publishing Game. London: Jonathan Cape.

Bourdieu, P. (1996). The Rules of Art. Cambridge: Polity.

Bourdieu, P. (2008). A conservative revolution in publishing. Translation Studies, 1(2), 123-153. https://doi.org/10.1080/14781700802113465

Campbell, E. (2016). Exploring autoethnography as a method and methodology in legal education research. Asian Journal of Legal Education, 3(1), 95-105. https://doi.org/10.1177/2322005815607141

Carr, D. (2005). Profile: The $33 \quad 1 / 3$ Series. Available at: http://www.stopsmilingonline.com/story_detail.php?id=360 (Accessed 29 June 2020).

Cerf, B. (1977). At Random: The Reminiscences of Bennett Cerf. New York: Random House.

Chandler, M. (2020). Auctions and pre-empts hotting up after lockdown, agents say. Available at: https://www.thebookseller.com/news/auctions-and-pre-empts-hotting-after-lockdown-agents-say-1211034 (Accessed 14 July 2020).

Childress, C. C. (2012). Decision-Making, Market Logic and the Rating Mindset: Negotiating Bookscan in the Field of US Trade Publishing. European Journal of Cultural Studies, 15(5), 604-620. https://doi.org/10.1177\%2F1367549412445757

Crisp, J. (2017). Sexism in Genre Publishing. Available at: https:/ /www.panmacmillan.com/blogs/science-fictionand-fantasy/sexism-genre-publishing-publishers-perspective (Accessed 6 July 2020).

Davies, G. (2004). Book Commissioning and Acquisition (2 $2^{\text {nd }}$ Edition). Abingdon: Routledge. https://doi.org/10.4324/9780203599075

Denzin, N. K. (2003). Performance ethnography: Critical pedagogy and the politics of culture. Thousand Oaks, CA: Sage. https://doi.org/10.4135/9781412985390

Doubleday, F. N. (1972). The Memoirs of a Publisher. New York: Doubleday \& Co.

Goodings, L. (2020). A Bite of the Apple: A Life with Books, Writers and Virago. Oxford: Oxford University Press.

Greenberg, S. (2015). Editors Talk About Editing: Insights for Readers, Writers and Publishers. Oxford: Peter Lang. https://doi.org/10.3726/978-1-4539-1523-3

Greenberg, S. (2018). The Poetics of Editing. London: Palgrave Macmillan. https://doi.org/10.1007/978-3-31992246-1

Harrap, G. (1935). Some Memories, 1901-1935. London: Harrap.

Korda, M. (1999). Another Life: A Memoir of Other People. New York: Random House.

Mahey-Morgan, C. (2020). We need to call out the lack of support and erasure of Black British voices. Available at: $\quad$ https://www.thebookseller.com/blogs/we-need-call-out-erasure-of-Black-British-voices-1205798 (Accessed 16 June 2020).

Marsden, S. and Squires, C. (2019). The First Rule of Judging Club...: Inside the Saltire Society Literary Awards. Journal of Cultural Analysis and Social Change, 4(2), 10. https:// doi.org/10.20897/jcasc/6354

Maschler, T. (2005). Publisher. Picador: London.

O’Brien, D., Laurison, D., Miles, A. and Friedman, S. (2016). Are the creative industries meritocratic? An analysis of the 2014 British Labour Force Survey. Cultural Trends, 25(2), 116-131. https://doi.org/10.1080/09548963.2016.1170943

Powell, W. 1985. Getting Into Print: The Decision-Making Process in Scholarly Publishing. Chicago: The University of Chicago Press.

Publishers Association. (2020). UK Publishing Industry Diversion \& Inclusion Survey 2019. Available at: https://www.publishers.org.uk/publications/diversity-survey-of-the-publishing-workforce-2019/ (Accessed 26 January 2021).

Ramdarshan Bold, M. (2016). An 'Accidental Profession': Small Press Publishing in the Pacific Northwest. Publishing Research Quarterly, 32, 84-102. https://doi.org/10.1007/s12109-016-9452-9 
Ramdarshan Bold, M. (2019). Inclusive Young Adult Fiction: Authors of Colour in the United Kingdom. London: Palgrave Macmillan. https://doi.org/10.1007/978-3-030-10522-8

Reed-Danahay, D. (2009). Anthropologists, Education, and Autoethnography. Reviews in Anthropology, 38(1), $28-47$. https://doi.org/10.1080/00938150802672931

Rodgers, M. (2017). The story of The Selfish Gene. Logos, 28(2), 44-55. https://doi.org/10.1163/1878-471211112129

Saha, A. (2017). The Rationalizing/Racializing Logic of Capital in Cultural Production. Media Industries Journal, 3(1), 1-16. https://doi.org/10.3998/mij.15031809.0003.101

Saha, A. and van Lente, S. (2020). Rethinking Diversity' in Publishing. London: Goldsmiths Press.

Sahim, S. (2015). The Unbearable Whiteness of Indie. Available at: https://pitchfork.com/thepitch/710-theunbearable-whiteness-of-indie/ (Accessed 30 June 2021).

Schaap, J. and Berkers, P. (2020). "You're Not Supposed to Be into Rock Music": Authenticity Maneuvering in a White Configuration. Sociology of Race and Ethnicity, 6(3), 416-430. https:/ / doi.org/10.1177/2332649219899676

Smith, S., Lee, C. et al. (2021). Inclusion in the Music Business: Gender \& Race/Ethnicity Across Executives, Artists \& Talent Teams. USC Annenberg.

Squires, C. (2017). Taste and/or big data?: post-digital editorial selection. Critical Quarterly, 59(3), $24-38$. https://doi.org/10.1111/criq.12361

Stewart, S. (2018). Making Evaluative Judgements and Sometimes Making Money: Independent Publishing in the 21st Century. Journal of Cultural Analysis and Social Change, 3(2), 10. https://doi.org/10.20897/jcasc/3991

Thompson, J. B. (2012). Merchants of Culture. Cambridge: Polity.

Tokumitsu, M. (2014). In the Name of Love. Available at: https://www.jacobinmag.com/2014/01/in-the-nameof-love/ (Accessed 8 August 2020).

Unwin, S. (1926). The Truth About Publishing. London: George Allen \& Unwin.

Usborne, P. (2020). Usborne named children's publisher of the year: some thoughts from Peter Usborne. Available at: https://usborne.com/blog/latest-usborne-news/usborne-named-children-s-publisher-of-the-year-aresponse-from-peter-usborne/ (Accessed 1 July 2020).

Vickers, M. (2002). Researchers as Storytellers: Writing on the Edge—and Without a Safety Net. Qualitative Inquiry, 8(5), 608-621. https:// doi.org/10.1177/107780002237007

Warburg, F. (1959). An Occupation for Gentlemen. London: Hutchinson.

Weldon, T. (2020). Books for Everyone, by Everyone: Our Inclusivity Action Plan, 2020. Available at: https:/ / www.penguin.co.uk/articles/company/news/2020/july/our-accelerated-inclusivity-action-plan.html (Accessed 11 July 2020).

Wilson, C. (2007). The Trouble with Indie Rock. Available at: https://slate.com/culture/2007/10/the-troublewith-indie-rock.html (Accessed 30 June 2021). 